\title{
Knowledge and attitudes in Puerto Rico concerning dengue prevention
}

\author{
Carmen L. Pérez-Guerra, ${ }^{1}$ Hilda Seda, ${ }^{1}$ Enid J. García-Rivera, ${ }^{1}$ \\ and Gary G. Clark ${ }^{1}$
}

Suggested citation Pérez-Guerra CL, Seda H, García-Rivera EJ, Clark GG. Knowledge and attitudes in Puerto Rico concerning dengue prevention. Rev Panam Salud Publica. 2005;17(4):243-53.

ABSTRACT Objective. Dengue has been endemic in Puerto Rico for three decades. Multiple educational and community-based efforts have been developed to inform the population about dengue prevention. We undertook this study to understand the community members' knowledge, attitudes, and practices related to dengue prevention and to elicit their ideas for future prevention campaigns.

Methods. A qualitative study based on grounded theory analysis was conducted between February and May of 2001. The study involved a total of 34 participants in four group interviews who had been identified through the Puerto Rico dengue surveillance system.

Results. In general, participants had correct knowledge about dengue prevention, but they did not associate the mosquitoes inside their houses with Aedes aegypti. Participants insisted that "neighbors" needed to control larval habitats, and the participants also asked the Government to fumigate.

Conclusions. The patterns of knowledge and opinion that emerged in the discussions can be arranged along an axis going from high levels of correct knowledge to low levels of correct knowledge about dengue and dengue hemorrhagic fever and related practices. There were few participants at either extreme. Three themes explained these patterns: misconceptions about dengue (based on previously delivered information), the "invisibility" of dengue (as compared to other diseases), and responsibility (individual and Government). Four strategies for preventive behaviors were recommended: developing community groups to identify community priorities on prevention, developing volunteer groups to deliver prevention messages, making house visits to demonstrate specific control measures, and conducting a complementary media campaign to support these strategies.

Key words Dengue; health education; Aedes; health knowledge, attitudes, practice; mosquito control; mass media; Puerto Rico.

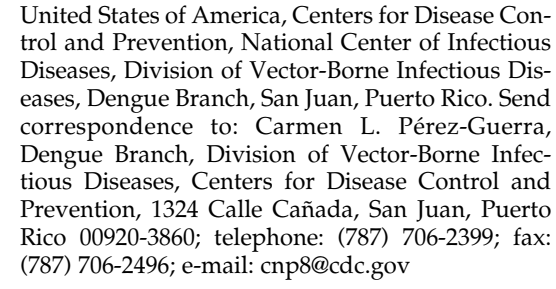

United States of America, Centers for Disease Control and Prevention, National Center of Infectious Diseases, Division of Vector-Borne Infectious Diseases, Dengue Branch, San Juan, Puerto Rico. Send correspondence to: Carmen L. Pérez-Guerra, Dengue Branch, Division of Vector-Borne Infectious Diseases, Centers for Disease Control and Prevention, 1324 Calle Cañada, San Juan, Puerto Rico 00920-3860; telephone: (787) 706-2399; fax: (787) 706-2496; e-mail: cnp8@cdc.gov

Dengue and its severe form, dengue hemorrhagic fever (DHF), is a viral disease that in the Americas is transmitted by Aedes aegypti mosquitoes. Every year an estimated 50 to 100 million cases of dengue and 500000 cases of DHF are reported worldwide (1). In 2002, 1000000 cases of dengue and more than 17000 DHF cases were reported in Latin America (2). In Puerto Rico, dengue is endemic, with 2400 to 4000 cases reported annually in nonepidemic years. The most recent islandwide epidemics occurred in 1994 and 1998. In 1994 there were 23693 cases reported (incidence of 6.7 per 
1000 population), and in 1998 there were 17000 cases reported (incidence of 4.8 per 1000 population) $(3,4)$.

As part of a comprehensive program that includes laboratory-based surveillance, planned emergency response, and education of the medical community, community participation has been proposed in Puerto Rico as a complement to the use of chemicals to control Ae. aegypti mosquitoes (5). Routine dengue prevention practices in Puerto Rico emphasize environmental sanitation through community cleanup campaigns, education, and house visits as well as fumigation when dengue cases are reported. The spraying of insecticides, which has proved to be ineffective since at least the 1970s (5-8), represents a great expenditure for many governments. Because the vector breeding sites are often found in residential premises, the need for active community participation in dengue prevention has been stressed (9). A barrier to successful community-based prevention is the limited input that communities usually have in defining the problem, setting priorities, and designing and evaluating prevention programs $^{2}$ (10). This situation, along with the frequent spraying of insecticides by ministries of health to "control" adults mosquitoes, has helped generate the general notion that the government is the only entity capable of conducting vector control activities; therefore, dengue prevention "is the government's responsibility" (8).

Government and private sector efforts to prevent dengue in Puerto Rico have included the development and distribution of educational materials to the general public and the implementation of community-based pilot projects. The pilot projects were designed to inform the public about dengue transmission, show how potential larval habitats could be elimi-

\footnotetext{
2 Kendall C. Community participation and health education for promoting environmental sanitation in dengue control programs. Meeting for the Preparation of Guidelines on the Prevention and Control of Dengue, Dengue Hemorrhagic Fever and Aedes aegypti in the Americas; 16-20 December 1991, Washington, D.C., United States of America.
}

nated or controlled, and transfer responsibility for controlling domestic mosquitoes from the Government to community members (11). However, additional efforts are often needed to facilitate wider community involvement in the planning, implementation, and evaluation of these programs.

Previous evaluations conducted with participants of community-based prevention projects found that Puerto Ricans have high levels of awareness about dengue, have taken preventive actions, and are ready to move to more sustained actions to eliminate and reduce mosquito breeding sites (12). To address the need for research among other segments of the population that have not been exposed to current pilot programs, we conducted a study with people from various geographic areas of the island to assess their knowledge, to understand local definitions of dengue transmission and control activities, to understand their attitudes towards dengue prevention, and to obtain their suggestions for improved strategies to promote the adoption of behaviors to eliminate or control Ae. aegypti larval habitats. Examining the population's knowledge and attitudes and the strategies that it recommends to promote dengue prevention will help health professionals to better understand community barriers to action, and factors that facilitate the adoption of recommended preventive actions. In turn, this deeper understanding will improve dengue prevention programs.

For our study we obtained the community's responses to two general questions: (1) What are the current concepts, attitudes, and behaviors of community members about dengue, DHF, and dengue/DHF prevention? (2) What ideas does the community have to increase the motivation of householders to adopt dengue prevention behaviors? A "grounded theory analysis" of the data coming out of four group interviews was conducted (13).

Grounded theory analysis is an inductive method that uses systematic content analysis to generate a theory from collected data. Open coding and axial coding procedures are carried out to develop core categories and subcategories and to establish relationships among core categories in order to develop the most salient themes and patterns. These themes and patterns are supported by excerpts from the transcripts and, using the method of constant comparison, are compared with results from earlier research. An integration of themes helps generate the theory that will explain the topic under investigation (13).

\section{MATERIALS AND METHODS}

We conducted group interviews in Spanish, which allowed participants to discuss their personal insights in an active, integrated, collective manner (13). Four municipalities (Arecibo, Patillas, San Juan, and Villalba) were selected, each with high dengue incidence from 1994 to 1999 and each representing a different geographic sector of the island. From these municipalities we selected a random sample of names of patients who had a positive immunoglobulin M (IgM) antibody test for dengue. The municipalities and the initial group participants were selected from the dengue surveillance system of the Centers for Disease Control and Prevention (CDC) Dengue Branch and Puerto Rico Department of Health. We telephoned persons on the list until we reached five from each of the municipalities who agreed to participate. In addition, an adult neighbor who lived in the third house to the right of the serologically diagnosed dengue case and who had not had dengue was contacted. If this neighbor refused to participate, we then contacted an adult from the next house to the right of the neighbor. We continued that process until 5 denguenegative participants were obtained from each municipality. We hoped to have 10 participants (5 dengue-positive and 5 dengue-negative) in each group session. A US\$ 25 payment to cover transportation costs was provided to each person who participated. The group sessions were conducted between February and May 2001. For ease of access, the sessions were con- 
ducted in Government facilities in the four municipalities.

We developed a guide with 20 openended questions that were based on the two general research questions. Prior to the first group interview in the four municipalities selected for our study, the guide was tested with residents from the municipality of Carolina. Ten members of a local church (five persons who said they had suffered from dengue in the past and another five persons who reportedly had not) were recruited to participate in a group session to validate the proposed interview guide. No changes were necessary, and the 20 questions are listed in Appendix 1.

The CDC institutional review board determined the protocol to be exempt from the United States Government regulations that require review for protection of human subjects. Informed consent was obtained from all the participants at the beginning of each session. The discussions were audiotaped, and the assistant moderator prepared written notes of these sessions. Tapes were transcribed verbatim and transcripts prepared for analysis.

Using the grounded theory analysis based on the transcripts and notes, we created 6 categories and 22 subcategories that emerged from the 2 central questions and the participants' responses to the 20 open-ended questions. The moderator created tables to code each response under the corresponding category and subcategory. Two additional analysts assisted in transcript coding. Each analyst coded the transcripts independently, and subsequently the moderator and the two analysts agreed on which responses were included in the coding by category and subcategory. The final results were summarized in a single table, from which themes and patterns of thought were identified. The quotes were translated into English for publication purposes.

\section{RESULTS}

To obtain 20 dengue-positive group interview participants, we made 95 telephone calls. From these 95 calls, we found that 53 persons (56\%) had changed telephone numbers or had moved, or their phone was out of service. Forty-two persons (44\%) were contacted, of whom 22 of them $(52 \%)$ agreed to participate and $20(48 \%)$ declined. We visited 30 neighbors who said that they had not had dengue, and 20 of them $(67 \%)$ agreed to participate. Of the 42 (22 positive and 20 negative) persons contacted who agreed to participate, a total of 34 persons (22 women and 12 men, 17 with a positive dengue test and 17 who said they had not had dengue) actually participated in the group interviews. After comparing household and neighborhood features (e.g., physical conditions of house structure, type of community, and community location) we concluded that most participants were of low to middle socioeconomic status.

Of 836 coded responses from 34 participants in the four group sessions, the analysts agreed to include 822 in the data analysis. A total of 14 responses were excluded because the analysts did not agree under which category to place them. The results are presented below in the six core categories generated by open coding. Twenty-two subcategories were also identified and were interconnected to the six core categories through an axial coding process.

\section{Most important biological, psychological, and social problems faced by the participants in their communities}

The category of the most important biological, psychological, and social problems was divided in two subcategories: (1) most important problems in the community and (2) most important health problems in the community (Table 1). In general the participants concluded that environmental issues were the most important problems in their communities, followed by family problems, lack of unity among neighbors, poor street conditions, and crime and safety. Chronic diseases, including depression, were the most important health problems mentioned by men, while "all health problems" were equally important to women. Dengue

TABLE 1. Most important biological, psychological, and social problems faced by participants in their communities, according to group interviews done in study of knowledge about and attitudes toward preventing dengue, Puerto Rico, 2001

\begin{tabular}{cl}
\hline \multicolumn{1}{c}{ Subcategory } & \multicolumn{1}{c}{ Problem } \\
\hline $\begin{array}{c}\text { Most important problems } \\
\text { in the community }\end{array}$ & Environmental issues \\
& Mosquitoes \\
Lack of cleanliness of houses, yards, & community areas, etc. \\
Inappropriate waste disposal by community & members in streets, rivers, and ravines \\
Used tires \\
Illegal dumps \\
Septic pits \\
Water-filled holes in streets \\
Broken water and sewer pipes \\
Family problems \\
Lack of unity among neighbors \\
Poor street conditions \\
Crime and safety \\
Chronic diseases \\
Most important health problems \\
in the community
\end{tabular}


was not mentioned as an important environmental or health problem. The most salient environmental problem mentioned by both women and men was mosquitoes, followed by a general lack of cleanliness (in houses, yards, community areas, etc.) and a lack of appropriate waste disposal by community members. Women emphasized that in the past the collection of refuse and garbage by the Government was not effective. Although the system has improved, people continue to throw garbage into the streets, rivers, and ravines. People also leave used tires in their patios and yards because they could be used in the future, or they are discarded in illegal dumps. Garbage thrown into the street covers the storm drains and, in combination with discarded tires and septic pits, contributes to the presence of rodents and mosquitoes and other insects. Water-filled holes in streets and broken water and sewer pipe systems were also associated with mosquito breeding.

\section{Knowledge about dengue, dengue hemorrhagic fever, and prevention}

In general, participants had correct knowledge about the following six subcategories, organized by descending level of knowledge: (1) Ae. aegypti breeding sites in their communities, (2) dengue/DHF symptoms, (3) the relationship of Ae. aegypti with garbage and containers with water, (4) the definition of dengue, (5) the definition of $\mathrm{DHF}$, and (6) the relationship between Ae. aegypti and dengue. Almost all the participants associated dengue/DHF with mosquitoes, saying dengue "is transmitted by a mosquito." However, some participants said dengue "is a mosquito" or "a mosquito bite," and others defined dengue as an illness or a virus transmitted by Ae. aegypti. Before having had dengue, some participants thought it was a common cold or the flu. They have heard the same comment from members of their communities. DHF was defined as "the most dangerous type of dengue, causing death." Dengue/DHF symptoms were reported as high fever, headache, eye pain, body and joint pain, weakness, rash or red dots, itching, nausea, vomiting, diarrhea, and bleeding. In addition, participants who were told by their physicians that they had DHF or had a relative who had had DHF reported that low platelet counts and high hepatic enzyme levels were associated with the disease. The duration of symptoms for both dengue and DHF ranged from one to two weeks.

When asked to describe the Ae. aegypti mosquito, almost all the participants described it with big legs and white stripes and being "bigger than the common mosquito." Most indicated that they did not know the mosquito's life cycle. However, most participants knew that it came from larvae, and they related Ae. aegypti with garbage and with containers with stagnant water. The participants also described the most important Ae. aegypti breeding sites in their communities (Table 2).

Participants showed confusion when discussing the type of water where Ae. aegypti likes to breed. Women mentioned clean or clear stagnant water, while men asserted that the water was dirty and stagnant or water that had been in the containers for a long time. Women said that the mosquito problem came from the yard, while men said that it came from the roofs, house eaves, abandoned houses, old cars, and junkyards.

\section{Attitudes about dengue, dengue hemorrhagic fever, and prevention}

The category of attitudes about dengue, dengue hemorrhagic fever, and prevention had five subcategories: (1) definition of "important problem," (2) definition of "prevention," (3) definition of "garbage," (4) ideas about dengue, and (5) responsibility for eliminating or controlling breeding sites. For women, a problem was important when it affected the family, a big group of people, or the community. For men it was important when "one sees it constantly" or "when a person sees and experiences the problem." One man said, "Dengue is out there, but when a mosquito bites you and you get infected, then it is important." All the participants agreed that chronic illnesses (e.g., diabetes, heart

TABLE 2. Most common Aedes aegypti breeding sites, their normal function or use, and location or condition, according to participants in group interviews done in study of knowledge about and attitudes toward preventing dengue, Puerto Rico, 2001

\begin{tabular}{lll}
\hline \multicolumn{1}{c}{ Breeding site } & Function/Use & \multicolumn{1}{c}{ Location or condition } \\
\hline $\begin{array}{l}\text { Containers } \leq 1 \text { gallon } \\
\text { Cans }\end{array}$ & Garbage & Outdoors \\
Bottles & Garbage & Outdoors \\
Flower/Plant vases & Not specified & Outdoors \\
$\begin{array}{l}\text { Animal drinking dishes } \\
\text { 5-gallon containers }\end{array}$ & To drink water & Outdoors \\
Pails & To store water & Uncovered (indoors or outdoors) \\
Buckets & To store water & Uncovered (indoors or outdoors) \\
Toilets & Out of service & Uncovered (indoors or outdoors) \\
55-gallon containers & & \\
Trash cans & To store water & Uncovered (indoors or outdoors) \\
Cisterns & To store water & With broken covers \\
Used tires & Not specified & Outdoors \\
Rivers/Ravines & Illegal dumps & Dry during drought or with garbage \\
Deserted houses & Not specified & With garbage and stagnant water \\
Yards & Not specified & With garbage and stagnant water \\
Roofs/Eaves & Not specified & With garbage and stagnant water \\
Storm drains & Not specified & With garbage and stagnant water \\
Discarded cars & Not specified & With garbage and stagnant water \\
Junkyards & Not specified & With auto parts filled with rainwater \\
\hline
\end{tabular}

a "Not specified" indicates that, according to the participants, these items did not have another, new use other than the normal use or function for which they were originally intended. 
and respiratory diseases, and cancer) were more important than dengue because more people suffer from them. However, almost all the participants described dengue as "very dangerous" and "horrible," and those who had experienced it themselves described the disease as "the worst thing they had gone through in their life," and they said that they "thought they were going to die."

While participants generally agreed that it is "everyone's responsibility to prevent dengue," some argued that dengue could not be prevented because people "are indifferent," "do not care," "are not serious," or "are tired of hearing about dengue." They also said that Puerto Rico is a tropical island, and is therefore a natural breeding site for mosquitoes. Some participants felt that people "do not feel worried" and "are indifferent" about dengue because they have not experienced it and because "there are too many papers [education materials] and talks giving information [on many subjects] that do not motivate people because this information is not serious [does not show deep thought]." Other participants asserted that dengue could be prevented if neighbors cleaned their own patios because "neighbors are the problem," and if the education is "concise, clear, and transmitted when needed."

Some participants defined prevention as "seeking guidance," "avoiding," or "taking safety measures before things happen." Others defined the term more specifically, describing the need to clean areas and to avoid having stagnant water. "Garbage" was defined as waste and things that cannot be reused or recycled, though participants also emphasized that "garbage" is defined by people's perception of an object and its use.

\section{Community behaviors related to dengue and dengue hemorrhagic fever}

The participants listed various dengue prevention behaviors that they and other community members prac-

TABLE 3. Current personal and household behaviors for preventing dengue, according to participants in group interviews done in study of knowledge about and attitudes toward preventing dengue, Puerto Rico, 2001

\begin{tabular}{ll}
\hline \multicolumn{1}{c}{ Items/lssues } & \multicolumn{1}{c}{ Prevention practice } \\
\hline Water-holding containers & Do not accumulate; eliminate \\
Discarded tires & Do not accumulate; eliminate; store in dry places \\
Animal drinking dishes & Clean; check regularly \\
Patios & Clean; check regularly \\
Containers used to store water (pails, buckets) & Turn upside down; cover; clean; check regularly \\
$\quad$ and trash cans & Discard water every two days \\
Stored water & Use \\
Repellents & Spray \\
Insecticides & Visit when suspect dengue \\
Doctor & Avoid these areas \\
Temporary pools of water with vegetation & Avoid these utensils \\
Utensils used by people with dengue &
\end{tabular}

TABLE 4. Specific actions to eliminate Aedes aegypti breeding sites, according to participants in group interviews done in study of knowledge about and attitudes toward preventing dengue, Puerto Rico, 2001

\begin{tabular}{ll}
\hline \multicolumn{1}{c}{ Potential breeding site } & \multicolumn{1}{c}{ Suggested actions } \\
\hline $\begin{array}{c}\text { Containers with stagnant water } \\
\text { (pails, buckets, drums) }\end{array}$ & $\begin{array}{l}\text { Cover containers } \\
\text { Discard water every two days } \\
\text { Pour in chlorine } \\
\text { Boil drinking water }\end{array}$ \\
Junkyards & $\begin{array}{l}\text { Cover junked cars with tarps } \\
\text { Spray insecticides } \\
\text { Develop laws to regulate them }\end{array}$ \\
Trash cans & $\begin{array}{l}\text { Punch holes to drain water } \\
\text { Cover }\end{array}$ \\
Roofs & $\begin{array}{l}\text { Promote daily garbage collection } \\
\text { Clean once a week, using chlorine tablets } \\
\text { Create a slope for drainage }\end{array}$ \\
Bires & $\begin{array}{l}\text { Build more drains } \\
\text { Recycle }\end{array}$ \\
Storm drains & $\begin{array}{l}\text { Put tires in dry places } \\
\text { Clean and pour in chemicals to kill mosquito larvae }\end{array}$ \\
\hline a Although these practices are not correct prevention actions, they are included because participants mentioned them \\
as suggested practices to eliminate or control breeding sites.
\end{tabular}

ticed (Table 3). In spite of doing these things, some participants still believed that dengue could not be prevented.

\section{Ideas to encourage the adoption of dengue prevention behaviors}

The participants suggested two different types of ideas to motivate community members to adopt dengue prevention behaviors, in the following subcategories: (1) specific action to eliminate $A$ e. aegypti breeding sites and (2) strategies to be implemented by the Government to promote dengue prevention. Table 4 summarizes the actions suggested for various breeding sites.

Women suggested house visits and group discussions in the community and did not recommend lectures or other formal presentations. Men recommended developing community 
groups as an effective method to disseminate correct dengue prevention messages to neighbors. Men also suggested enacting laws that would mandate fines for persons who don't control mosquito breeding sites. Women repeatedly insisted that the Government should spray with insecticides, affirming that "prevention should be given to the community since the problem is generated in the patios, but if water is in the streets, the Government should spray insecticides." In addition, women suggested recycling as a way to prevent dengue, but asserted that the Government no longer had a recycling program in their areas. Still other participants stated that recycling would not solve the problem because not everybody likes to recycle because of the extra duties it adds to their daily routine, there is a lack of Governmental coordination of recycling sites, and the sites are not accessible.

\section{Design for a dengue prevention mass media campaign}

The category of design for a dengue prevention mass media campaign included seven subcategories: (1) evaluation of previous dengue prevention campaigns, (2) messages to motivate the community to eliminate and control Ae. aegypti breeding sites, (3) target audience, (4) best spokesperson, (5) best media, (6) best strategies, and (7) best time to transmit dengue prevention messages.

When asked if they remembered earlier dengue prevention campaigns, the participants mentioned four things: two public service announcements (PSAs), a DHF poster showing a baby bleeding from the nose, and a poster showing four specific dengue prevention actions.

One of the PSAs that the participants remembered was "Carmencita," and the other was "Los Cazadores" ("The Hunters"). Broadcast in the 1980s, "Carmencita" was the story of a girl who died of DHF. Narrated by a well-known Puerto Rican actor, the PSA showed Carmencita's parents arriving home after the burial of their daughter, and the larval habitats found in their house. The narrator discussed dengue, DHF, behaviors to control potential breeding sites (such as discarding tires and cleaning an ornamental fountain filled with water), and the responsibility that householders have in dengue prevention. Most of the study participants said that "Carmencita" was very good because it caused "impact" and "awareness" in the public about death as a result of having dengue. However, other participants thought that the "Carmencita" PSA was "horrible." It made them aware of the danger that dengue presented to their children, but it also made them feel afraid.

"Los Cazadores" was a 1998 PSA that showed two boys going on a "safari" to look for Ae. aegypti breeding sites in their yard. The boys were equipped with a tray, an eye dropper to collect mosquito larvae, a magnifying glass, a flashlight, and a sponge. The PSA was intended to teach people how to look for larval habitats and rid containers of eggs and larvae. One participant said that this PSA needed "more emotion" and needed to "better explain" the relationships among stored water, larvae, mosquitoes, and dengue.

The participants repeatedly stressed that the best strategies to distribute prevention messages were group discussions in the community, done in association with a mass media campaign. Most participants said that a new campaign should have more "aggressive" messages than in "Los Cazadores." In order to be effective, the messages should be specific, show worst-case scenarios, be "real," present testimonials, and be repeated frequently. The messages should be varied and short, with visuals and colors, and show the relationship of water, larvae, and the adult mosquito. At the same time, they should make a strong impression and be broadcast with sensitive words and images that appeal to the viewers' feelings. Participants said messages should be focused on the family and stress that dengue could be prevented, thus avoiding illness in the family.
Participants thought the target audience should be "everyone" because prevention is everyone's responsibility. The preferred spokesperson was a child or adolescent because they often stimulate awareness in parents. Other suggested spokespersons included people who have had dengue, a celebrity, or health professionals.

The best communication channel was said to be television, followed by newspapers and short, printed handouts with concise and clear information to be distributed in public places. The best time to air television messages would be 5-9 p.m., after people have returned from work, during popular programming (e.g., for women, soap operas (novelas), and for men, newscasts). Group discussions in the community should be held between 7 and 9 p.m. for working people. For unemployed persons, who often go to social services and medical appointments in the mornings, the discussions should be in the afternoon.

\section{DISCUSSION AND CONCLUSIONS}

Three main themes came out of our study. The first theme concerned misconceptions about dengue, including in such areas as the description of the Ae. aegypti mosquito, the cleanliness or clarity of water in the larval habitat, cleanliness as the central action to prevent dengue, and the relation that dengue has with other illnesses. The second theme was the "invisibility" of dengue in contrast to the predominance of information about chronic illnesses in the media and amongst health professionals. The third theme had to do with issues surrounding individual responsibility for dengue prevention. These themes were key in determining the participants' perspectives on community participation in dengue prevention.

\section{Major misconceptions about dengue}

Participants demonstrated a high level of correct knowledge about 
dengue symptoms, the relationship of dengue with mosquitoes, and the relationship of the vector mosquito with garbage and containers with stagnant water. Incorrect knowledge, however, is still intertwined with other facts, resulting in four major misconceptions that relate to the public's attitudes and actions: (1) Ae aegypti is bigger than the common mosquito, (2) clean water is where Ae. aegypti likes to breed, (3) "cleanliness" by itself is the correct measure needed to prevent dengue, and (4) dengue is like a common or bad cold.

In many educational materials the visual image of the mosquito was enlarged in order to help householders recognize the mosquito and look for breeding sites in their premises, but it had the opposite effect. Because of the distorted presentation of the mosquito's size, householders do not associate the adult mosquitoes inside their homes with dengue or with the larvae breeding in containers found in their yards. Consequently, they do not look for and control potential larval habitats. Moreover, there are other mosquitoes (e.g., Culex) that are present inside the houses along with $A e$. aegypti, and the public is more concerned about the nuisance of their bite than about getting dengue. Accordingly, people think that the only way to control mosquito bites is to use repellents and to have the Government spray insecticides. Although many residents know that dengue can be prevented by eliminating breeding sites, they do not control larval habitats because this action is not perceived as an effective practice for reducing the number of adult mosquitoes. Lloyd et al. (14) found that it was important for householders in the city of Mérida, Mexico, to correctly identify the Ae.aegypti mosquito in order to eliminate its breeding sites. Householders also needed to be able to understand the presence of other species of mosquitoes after prevention control activities, and that these mosquitoes were not a hazard for transmitting dengue. The presence of mosquitoes after the Mérida householders implemented control measures to prevent dengue decreased their perception of success and made them think that dengue cannot be prevented.

Water was the subject of much discussion in our Puerto Rico group sessions, including whether clean or clear water was preferred by Ae. aegypti. The misconception that Ae. aegypti breeds only in clean or clear water is associated with the drawings and photographs shown in earlier educational materials, where the water appeared to be very clear or clean. Entomologic surveys have shown that larvae are found in clear or clean stagnant water that over time can gets darker as leaves and other organic materials fall into it. This habitat is optimal, as it provides organic materials for larval development. References in earlier educational materials to "clean" or "clear" water as the preferred breeding habitat influence the public's knowledge about where to look for larval habitats. New educational materials should stress the importance of properly covering containers for storing water, and of discarding all types of water (clean, clear, darker, or dirty) that the householders will not use.

The third major misconception is related to "cleanliness" as the central concept in dengue prevention. Many authors have stressed the importance of collecting refuse and of cleaning specific containers to remove mosquito eggs, larvae, and pupae (15-17). Participants asserted that general "cleanliness" is an effective way to prevent dengue transmission, but they did not consider particular cleaning practices for controlling specific larval habitats. Consequently, a house or a patio can be "clean" but still have mosquito larvae present in various containers. The promotion of "cleanliness" is grounded in decades of health prevention programs that encourage good-hygiene practices that are focused on germs and bacteria. Winch et al. (9) found that health education messages that were linked to the lack of hygiene in homes led women to feel pressured about their ability to maintain houses that were clean and free of disease. As a result, the women rejected the vector control prevention practices.
The fourth major misconception associates dengue with a common cold or flu-like illness. Common colds or severe colds (known as monga in Puerto Rico) are not considered serious conditions by Puerto Ricans; therefore, the association of dengue with these illnesses decreases its importance and reduces the importance of adopting preventive behaviors. Earlier research in Colombia (18), the Dominican Republic $(19,20)$, Mexico (10, 14), and Puerto Rico (21) found that participants confused dengue with other febrile and respiratory illnesses. These illnesses were not seen as serious by the participants, and the participants did not relate the illnesses to the presence of mosquitoes. Therefore, the participants did not take effective prevention actions to protect themselves from dengue (14, 18-20).

\section{The "invisibility" of dengue}

The second primary theme that came out of our group interviews was the "invisibility" of dengue in Puerto Rico. Chronic diseases have become a priority for the public because of their high incidence, associated deaths, and the heavy attention from health professionals, who have provided large amounts of information in educational materials, the mass media, and health forums. In this environment, dengue almost disappears from public view. The discussion group participants also said that much information about different subjects is distributed, but that this information often does not seem to be "serious," or analyzed in depth. Furthermore, the participants in the group interviews felt that dengue was important to Government officials when the rainy season arrived. Consequently, dengue's visibility and announcements promoting community prevention actions depended on the Government's recognition and reporting of outbreaks and epidemics. In the past, the Government delayed its response despite the early warnings of epidemic activity by its surveillance system (11). The amount of information and focused guidance about other 
chronic illnesses and health topics delivered to the population made dengue "invisible" and prompted feelings of indifference and exhaustion among community members. Information about dengue provided through educational materials, lectures, and meetings prescribed preventive behaviors to the population, but there was no apparent link between the information delivered and the community's priorities and the residents' needs to solve the problem. As a result, these materials are often ignored by the public. Winch et al. (10), Rifkin (22), and many others have emphasized the need for health educators and program planners to legitimize and respect local knowledge and concerns in the development and implementation of effective communication and community participation interventions.

\section{Responsibility for dengue prevention}

The third primary theme that came out of our group interviews had to do with responsibility for dengue prevention. In the past in many countries around the world, dengue was a responsibility of the government and was handled by a vertically organized control program. However, the elevated costs of that approach and concerns about the need for sustainable prevention prompted many governments to shift the responsibility to the community and householders $(7,11)$. Many dengue prevention campaigns in the Americas have succeeded in raising awareness about individual responsibility to eliminate or control Ae. aegypti breeding sites $(10,12,14)$. The participants in our Puerto Rico group interviews asserted that dengue prevention was everyone's responsibility, but at the same time they perceived that "the neighbor" was the problem. If either the Government shifts responsibility to householders or people blame their neighbors, that promotes an individualistic approach to dengue prevention by placing the burden for action on the person who has to clean up and eliminate potential breeding sites. This fails to acknowledge that dengue prevention is not a problem that one can solve alone. Rather, prevention is a joint venture, in which the householders, the community, the private sector, and the Government should all play active roles.

The CDC has implemented a community-based education program in Puerto Rico that has included the participation of social scientists and the private sector in developing educational materials and pilot prevention projects. These efforts have proven effective in building awareness and a sense of responsibility among the public (11). However, further steps are needed to increase community participation within neighborhoods, with householders and private and public sector allies cooperating in planning, implementing, and evaluating activities. This approach is preferable to community-based projects for the general public in which health professionals develop and carry out the prevention projects based on earlier information gathered from the population.

\section{Conclusions}

The purpose of our study in Puerto Rico was to understand the knowledge, attitudes, and behaviors of the community concerning preventing dengue, and to solicit the community members' recommendations for improving existing dengue prevention programs. The patterns of responses of the 34 participants in the group interviews can be arranged along an axis that goes from a great amount of correct knowledge and associated practices to a situation of little knowledge, and with few people being at either extreme.

The gaps in knowledge were surprising. Although almost everyone knew that dengue is transmitted by a mosquito, even the best informed admitted they could not recognize the Aedes aegypti mosquito if they saw it. While recognizing the responsibilities that individuals, the community, and the Government have in eliminating mosquito breeding sites, almost every- one also insisted on having fumigation done by the Government. Some of the well-informed participants were also skeptical about the preventability of dengue. Even persons who mentioned erroneous alternative means of transmission or who knew little about dengue symptoms considered it a dangerous disease that was somehow related to mosquitoes.

An integration of the three themes discussed above (misconceptions, invisibility, and responsibility for prevention of dengue) suggests that dengue is not important to the general population in Puerto Rico. Overshadowed by chronic diseases, dengue has become almost invisible to the community, resulting in public indifference to dengue information. In addition, educational materials that showed enlarged or distorted images of the Ae. aegypti mosquito have created confusion over which mosquito transmits dengue. Correct information on that is essential if participants are to eliminate larval habitats. Earlier materials also focused on prescribing preventive actions, but were not seen as complementary to the promotion of the involvement of community members in solving dengue problems. These were the greatest barriers to dengue prevention that emerged from the group discussions.

The participants in the group interviews recommended four activities to deal with the misconceptions about dengue and its invisibility and the question of who is responsible for preventing dengue. These activities are: house visits, group discussions in the community, involving community groups to work in their neighborhoods, and a complementary mass media campaign to strengthen the actions taken by the community and increase the public's awareness of dengue prevention. These strategies should be considered in the design of future community-based dengue prevention programs.

A model of a neighborhood participation project based on the recommended strategies should be developed and evaluated to test its efficacy and sustainability. The model should 
incorporate group discussions with community members so as to assess and better understand community priorities related to dengue, to clarify misconceptions, and to promote the creation of community groups. In coordination with Government officials, community groups could conduct house visits and explain to their neighbors where to look for breeding sites. Community groups could also describe to their neighbors the specific control measures that are recommended to eliminate or control the various types of larval habitats (12) as well as the relationship among eggs, larvae, and adult mosquitoes in or near their houses. To complement the community participation activities, educational materials and messages should be developed and directed to target audiences. These materials and messages should show the specific water containers that are locally important in producing mosquitoes, the person who is responsible for the containers, the containers' usage in the household, and the desired control measure to apply with the containers. Targeted materials are needed since the public might interpret general educational materials in different ways. New mass media campaigns should also emphasize information shared in the house visits, including the relation- ship that garbage and containers have with stagnant water, the association between larvae and the adult mosquito inside houses, and the relationship between mosquito bites and a person with dengue (10). The messages need to send cues or reminders to the community about the specific behaviors that will control breeding sites, instead of emphasizing overall cleanliness as a central concept $(8,12)$. The messages should also indicate when to implement these behaviors, and the messages should provide positive feedback to those practicing them. Messages should also clearly emphasize that dengue is dangerous, can be fatal, and is endemic to Puerto Rico, and that localized outbreaks occur in most years. Information about local outbreaks should be disseminated through local newspapers to notify the public when to implement the desired behaviors (12). In addition, the messages should stress individual responsibility in dengue prevention, and that preventing dengue is a better strategy than trying to cure it.

The grounded theory method highlights the process of constantly comparing the study results with earlier research and later research. Through this process, the researcher can continue to confirm the study results or the developed theory. For this reason and because each of the four group interviews included both men and women with and without personal experience with dengue, further studies should be conducted with the following four segmented audiences: (1) women with prior dengue infection, (2) women without prior dengue infection, (3) men with prior dengue infection, and (4) men without prior dengue infection. Using focus groups, the principal investigator (CLPG) has explored in detail other aspects of dengue prevention, such as solid waste disposal problems, cleanliness, and differences between the genders. The data from these new focus groups are now being analyzed. Future plans include conducting knowledge, attitudes, beliefs, and behaviors surveys to determine if the results from the group interviews and focus groups can be generalized to the entire population of Puerto Rico.

Acknowledgements. We gratefully acknowledge the cooperation of the respondents as well as the comments and suggestions made by José G. Rigau-Pérez, of the CDC Dengue Branch, San Juan, Puerto Rico, and by Emily Zielinski-Gutiérrez, of the CDC Division of Vector-Borne Infectious Diseases, Fort Collins, Colorado.

\section{REFERENCES}

1. World Health Organization. Prevention and control of dengue and dengue haemorrhagic fever: comprehensive guidelines. New Delhi: WHO/Regional Office for South-East Asia; 1999. (WHO/SEARO/29).

2. Guzman MG, Kouri G. Dengue and dengue hemorrhagic fever in the Americas: lessons and challenges. J Clin Virol. 2004;27(1): $1-13$.

3. Rigau-Pérez JG, Vorndam AV, Clark GG. The dengue and dengue hemorrhagic fever epidemic in Puerto Rico, 1994-1995. Am J Trop Med Hyg. 2001;64(1,2):67-74.

4. Rigau-Pérez JG, Ayala-López A, GarcíaRivera EJ, Hudson SM, Vorndam AV, Reiter $\mathrm{P}$, et al. The reappearance of dengue- 3 and a subsequent dengue- 4 and dengue- 1 epidemic in Puerto Rico in 1998. Am J Trop Med Hyg. 2002;67(4):355-62.

5. Gubler DJ, Casta-Vélez A. A program for prevention and control of epidemic dengue and dengue hemorrhagic fever in Puerto Rico and U.S. Virgin Islands. Bull Pan Am Health Org. 1991;25:237-47.

6. Reiter P, Gubler DJ. Surveillance and control of urban dengue vectors. In: Gubler DJ, Kuno $\mathrm{G}$, eds. Dengue and dengue hemorrhagic fever. Wallingford: CAB International; 1997. Pp. 425-62.

7. Gubler DJ. Dengue. In: Monath TP, ed. The arboviruses: epidemiology and ecology. Boca Raton: CRC Press; 1988. Pp. 223-60.

8. Winch PJ, Kendall C, Gubler DJ. Effectiveness of community participation in vector-borne disease control. Health Policy Planning. 1992; $7(4): 342-51$

9. Winch PJ, Lloyd LS, Hoemeke L, Leontsini E. Vector control at the household level: an analysis of its impact on women. Acta Tropica. 1994;56:327-39.

10. Winch PJ, Lloyd LS, Godas MD, Kendall C. Beliefs about the prevention of dengue and other febrile illness in Mérida, Mexico. J Trop Med Hyg. 1991;94:377-87.

11. Gubler DJ, Clark GG. Community involvement in the control of Aedes aegypti. Acta Tropica. 1996;61:169-79.

12. Winch PJ, Leontsini E, Rigau-Pérez JG, RuizPérez M, Clark GG, Gubler DJ. Communitybased dengue prevention programs in Puerto Rico: impact on knowledge, behavior, and residential mosquito infestation. Am J Trop Med Hyg. 2002;67(4):363-70.

13. Patton MQ. Qualitative research and evaluation methods. 3rd ed. Thousand Oaks: Sage Publications; 2002.

14. Lloyd LS, Winch P, Ortega-Canto J, Kendall C. The design of a community-based health education intervention for the control of Aedes aegypti. Am J Trop Med Hyg. 1994;50(4): 401-11.

15. Sherman C, Fernández EA, Chan AS, Lozano $\mathrm{RC}$, Leontsina E, Winch PJ. La untadita: a pro- 
cedure for maintaining washbasins and drums free of Aedes aegypti based on modification of existing practices. Am J Trop Med Hyg. 1998;58(2):257-62.

16. Fernández EA, Leontsini E, Sherman C, Chan AST, Reyes CE, Lozano RC, et al. Trial of a community-based intervention to decrease infestation of Aedes aegypti mosquitoes in cement washbasins in El Progreso, Honduras. Acta Tropica. 1998;70:171-83.

17. Yasumaro S, Silva ME, Andrighetti MTM, Macoris MLG, Mazine CAB, Winch PJ. Community involvement in a dengue prevention project in Marília, Sao Paulo State, Brazil. Human Organ. 1998;57(2):209-14.
18. Fajardo P, Monge CA, Lozano G, Realpe O, Hernández LE. Nociones populares sobre "dengue" y "rompehuesos", dos modelos de la enfermedad en Colombia. Rev Panam Salud Publica. 2001;10(3):161-8.

19. Gordon AJ. Mixed strategies in health education and community participation: an evaluation of dengue control in the Dominican Republic. Health Educ Res Theory Practice. 1988;3(4):399-419.

20. Gordon AJ, Rojas Z, Tidwell M. Cultural factors in Aedes aegypti and dengue control in Latin America: a case study from the Dominican Republic. Int Quart Community Hlth Educ. 1990;10:193-211.
21. Koss J. Final report: innovative educational approaches to the prevention of dengue and dengue hemorrhagic fever in Puerto Rico. Albuquerque: University of New Mexico, Department of Psychiatry; 1988.

22. Rifkin SB. Paradigm lost: toward a new understanding of community participation in health programmes. Acta Tropica. 1996;61: 79-92.

Manuscript received 10 June 2004. Revised version accepted for publication 7 February 2005.

\section{APPENDIX 1. The 20 open-ended questions that were used to guide the group interviews to identify knowledge and attitudes regarding dengue prevention, Puerto Rico, 2001}

1. Usually there are problems in the community that the residents would like to solve. In your community, what would be the most important problems?

2. How do people define an "important problem"?

3. What health problems are important for you?

4. How do you describe dengue, and why?

5. What do people think about or have they heard about dengue in your community?

6. What do you know about dengue hemorrhagic fever?

7. How does the Aedes aegypti mosquito relate to dengue and dengue hemorrhagic fever?

8. What do you think when you hear the word "prevention"?

9. How do people think that they can prevent dengue?

10. How does the Aedes aegypti mosquito relate to garbage and to containers with stagnant water?

11. How do you define the word "garbage"?

12. What would be the most common containers that could serve as mosquito breeding sites in your community?

13. How could those containers be taken care of or eliminated to avoid mosquito breeding sites?

14. Who would be the persons responsible for taking care of or eliminating those containers?

15. Do you remember previous dengue campaigns? What do you think about them?

16. What kind of message could motivate people to take care of and pick up or eliminate the containers that are breeding sites for mosquitoes?

17. To whom do you think this messages should be directed, and why?

18. Who do you think should be the spokesperson to motivate the community to prevent dengue? For example, a community person, an actor/actress, a health professional, etc.?

19. What would be the best media to deliver the message, and why? For example, radio, TV, movies, newspapers, magazine, etc.?

20. What would be the best time of the day to deliver the message? 
RESUMEN Objetivo. El dengue ha sido endémico en Puerto Rico durante tres decenios, y varias iniciativas educativas y comunitarias se han puesto en marcha con objeto de informar a la población sobre la prevención de la enfermedad. Realizamos la presente

Conocimientos y actitudes en Puerto Rico en torno a la prevención del dengue investigación con el fin de entender los conocimientos, actitudes y prácticas de la comunidad en torno a la prevención del dengue y de recoger sus ideas acerca de futuras campañas de prevención.

Métodos. Entre febrero y mayo de 2001 se llevó a cabo un estudio cualitativo basado en el método inductivo conocido por "categorización mediante teoría generada" [grounded theory analysis]. El estudio se efectuó con 34 participantes de cuatro entrevistas en grupo, todos ellos identificados mediante el sistema de vigilancia del dengue de Puerto Rico.

Resultados. En términos generales, los participantes tenían conocimientos adecuados acerca de la prevención del dengue, pero no asociaban los mosquitos que había dentro de las viviendas con Aedes aegypti. Repetían con insistencia que "el vecino" tenía que controlar los hábitat larvarios, y también le pidieron al Gobierno que fumigara. Conclusiones. Los conocimientos y opiniones que afloraron en las discusiones mostraron ciertos patrones. Colocados a lo largo de un eje, estos revelaron un espectro desde muchos hasta muy pocos conocimientos que fuesen acertados acerca del dengue, la fiebre hemorrágica del dengue y las prácticas que deben observarse en conexión con estas afecciones. Hubo pocos participantes en un extremo $u$ otro del espectro. Tres temas explicaron los patrones observados: ideas equivocadas en torno al dengue (basadas en información impartida anteriormente), la "invisibilidad" del dengue (por comparación con otras enfermedades), y la responsabilidad (individual y del Gobierno). Se recomendaron cuatro estrategias encaminadas a fomentar conductas de tipo preventivo: crear grupos comunitarios que identificaran las prioridades de la comunidad en materia de prevención; formar grupos de voluntarios que impartieran mensajes con fines preventivos; hacer visitas domiciliarias para demostrar ciertas medidas de control, y llevar a cabo una campaña de publicidad complementaria orientada a reforzar estas estrategias.

Palabras clave Dengue; educación en salud; Aedes; conocimientos, actitudes y prácticas en salud; control de mosquitos; medios de comunicación de masa; Puerto Rico.

\section{ASAMBLEA MUNDIAL DE SALUD DE LOS PUEBLOS}

\section{Fecha: $\quad 17-23$ de julio de 2005 \\ Lugar: Cuenca, Ecuador}

El Movimiento de Salud de los Pueblos (MSP) es una coalición de organizaciones de la sociedad civil, organizaciones no gubernamentales, activistas sociales, profesionales de la salud, académicos e investigadores que respaldan la Declaración para la Salud de los Pueblos. Creado en 2000, el MSP busca devolverles a la salud integral y el desarrollo con equidad un lugar prioritario en las políticas de salud mediante una atención primaria de salud de carácter integral, como la proclamada en Alma Ata.

En julio de 2005, el MSP celebrará en Cuenca, Ecuador, la II Asamblea Mundial de Salud de los Pueblos como culminación de todo un proceso de reflexiones, discusiones y debates en torno a los factores que determinan la salud y el bienestar de las poblaciones. El diseño de una agenda para lograr una salud renovada será una de las principales metas de la Asamblea. Los temas tratados en ella, cuyo lema será "iLas voces de la tierra nos convocan!: construyamos un mundo saludable", abarcan una gama muy amplia: la salud como derecho humano fundamental; la militarización y la ocupación; la degradación ambiental; las pandemias emergentes y reemergentes; la equidad, la pobreza y la salud; la violencia social y política; la salud en manos del pueblo; la salud en el trabajo; la medicina tradicional y bioenergética; el género, la reforma del sector de la salud, entre otros. Cada uno de los temas se abordará mediante a) exposiciones analíticas ilustradas; b) relatos y testimonios de representantes comunitarios, activistas del movimiento y líderes sociales; c) fotografías, dibujos, pinturas, artesanías, carteles, sesiones, rituales, música, expresiones dramáticas, documentos, libros, videos, etc.

Además de las actividades anteriores, se han previsto diversos eventos especiales, entre los que destacan el Foro Mundial de la Niñez, el Festival de la Esperanza y la Alegremia, la Declaración de los Pueblos Originarios, y el lanzamiento del Informe Alternativo de la Salud en América Latina.

\section{Información:}

Dr. Arturo Quizhpe

Coordinador II Asamblea Mundial de Salud de los Pueblos

Telefax: 593-7-2841865 • Fax: 593-7-2881406

Correo electrónico: asamblea05@yahoo.com • pha2@phmovement.org

Internet: http://www.iphcglobal.org/index_es.htm • http://www.phmovement.org/pha2/ 